\title{
Synthesis of Polystyrene and Poly(methyl methacrylate) Each with a Phenyl Seleno Group at Terminal Chain End by Radical Polymerization in the Presence of Benzyl Phenyl Selenide as a Photoiniferter
}

\author{
Tae Seok Kwon, Shuji Kondo, ${ }^{\dagger}$ Hideo Kunisada, \\ and Yasuo $\mathrm{YuKI}^{\dagger+}$ \\ Department of Materials Science and Engineering, Nagoya Institute of Technology, \\ Gokiso-cho, Showa-ku, Nagoya 466-8555, Japan
}

(Received October 27, 1997)

\begin{abstract}
The photopolymerization of styrene with benzyl phenyl selenide proceeded smoothly to give polystyrene having benzyl and phenylseleno groups at $\alpha$ - and $\omega$-chain ends, respectively, and the degree of functionality was 0.95 . In a limited range of conversion, both the polymer yields and number average of molecular weights $\left(\bar{M}_{n}\right)$ increased with the reaction time and the $\bar{M}_{n}$ linearly increased with yield. The addition of styrene to the polystyrene with irradiation increased the molecular weight of the polymer. In the photopolymerization of methyl methacrylate, similar polymerization behavior was observed. The tacticity of the poly(methyl methacrylate) was in good agreement with that prepared by radical mechanism. Photoirradiation of polystyrene having phenylseleno group at the $\omega$-end in the presence of methyl methacrylate effectively afforded a block copolymer of styrene and methyl methacrylate.
\end{abstract}

KEY WORDS Radical Polymerization / Benzyl Phenyl Selenide / $p$-Methoxybenzyl $p$-Trimethylsilylphenyl Selenide / Photoiniferter / Polymeric Photoiniferter / Block Copolymer /

End functional polymers are useful precursors for novel block, graft and star polymers. The synthesis of end functional polymers are conventionally prepared by anionic, cationic, and radical polymerization. ${ }^{1-11}$ Preparation by radical polymerization with iniferter method is quite convenient and hence widely used. ${ }^{12-16}$

Otsu and coworkers ${ }^{17-19}$ proposed iniferter for the design of the polymer chain end structure. An iniferter is an initiator which also functions as chain transfer agent and/or primary radical terminator. It is attractive for preparing simple block copolymers and more complex polymer architectures using various monomers which do not polymerize by an ionic mechanism. ${ }^{20-23}$ Iniferters mainly use organic sulfur compounds such as tetraalkylthiuram disulfides, dithiocarbamates, and tetramethylene disulfide.

We recently reported that photopolymerization of styrene in the presence of diphenyl diselenide, ${ }^{24}$ similar to the case of tetraalkylthiuram disulfides ${ }^{25}$ to afford polystyrene carrying phenylseleno groups at both chain ends (P-A) (eq 1). By the irradiation of light to the polymers with selenide moieties (P-A) in styrene, polystyrene with higher molecular weight (P-B) was obtain-

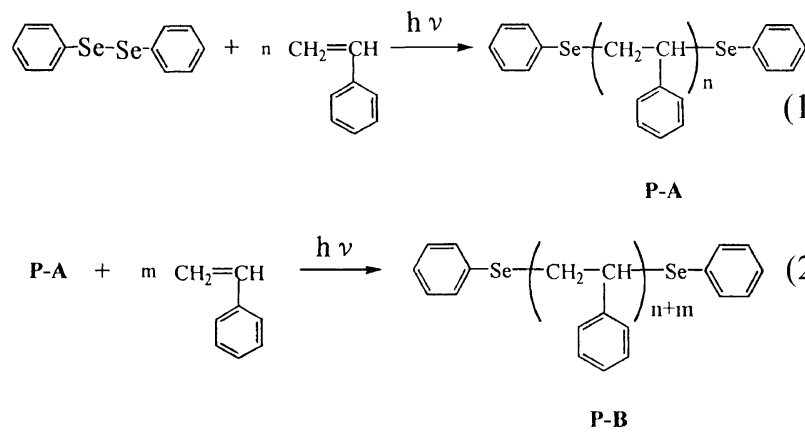

ed (eq 2).

The carbon-selenium bond thus undergoes homolytic cleavage on photoirradiation to afford phenylseleno and carbon radicals, and styrene monomers insert to these radicals to afford polymer with higher molecular weight. Polystyrenes having hydrogen or carbon-carbon double bonds at both chain ends were prepared with the elimination of phenylseleno groups using important features of organic selenium compounds. ${ }^{26,27}$ Chu et $a{ }^{28}{ }^{28}$ reported that the homolysis of benzylic carbon and selenium bond as well as diselenide bond occurs in the photolysis of dibenzyl diselenide. Therefore, we expect that benzyl phenyl selenide works as a photoiniferter in radical polymerization.

This paper deals with the synthesis of the polystyrene and poly(methyl methacrylate) with a phenylseleno group at $\omega$-chain end with benzyl phenyl selenide under photochemical conditions and applications to the synthesis of block copolymer.

\section{EXPERIMENTAL}

\section{Materials}

Styrene and methyl methacrylate were purified by the ordinary method and distilled in a stream of nitrogen just before use. Solvents were purified by distillation after appropriate drying. $p$-Trimethylsilylbromobenzene was prepared from the reaction of $p$-lithiobromobenzene and chlorotrimethylsilane according to the literature ${ }^{29}$ and was purified by distillation. Other reagents were obtained commercially and used without further purification.

\footnotetext{
+ Deceased August 5, 1997.

${ }^{\dagger}$ To whom all correspondence should be addressed (Fax: +81-52-735-5294)
} 
Synthesis of Benzyl Phenyl Selenide (1)

To a solution of phenylmagnesium bromide prepared from magnesium $(4.80 \mathrm{~g}, 0.20 \mathrm{~mol})$ and bromobenznene $(31.4 \mathrm{~g}, 0.20 \mathrm{~mol})$ in tetrahydrofuran (THF) $(60 \mathrm{ml})$, was added gradually selenium powder $(14.8 \mathrm{~g}, 0.19 \mathrm{~mol})$. Stirring was continued for additional $1 \mathrm{~h}$. To this reaction mixture, benzyl bromide $(29.1 \mathrm{~g}, 0.17 \mathrm{~mol})$ was added slowly with cooling, and stirred for $8 \mathrm{~h}$ at room temperature. A solution of ammonium chloride $(10.7 \mathrm{~g}$, $0.20 \mathrm{~mol})$ in water $(50 \mathrm{ml})$ was added to the reaction mixture, extracted with ether and dried over anhydrous sodium sulfate. Evaporation of the solvent gave a solid. This solid was recrystallized from ethanol. Yield was $11.8 \mathrm{~g}(24 \%), \mathrm{mp} 27.5^{\circ} \mathrm{C}$. (lit. ${ }^{30} 33.5-34^{\circ} \mathrm{C}$ ). ${ }^{1} \mathrm{H}$ NMR $\left(\mathrm{CDCl}_{3}\right) \delta 4.10\left(\mathrm{~s}, \mathrm{CH}_{2}, 2 \mathrm{H}\right), 7.15-7.52$ (br s, $2 \mathrm{C}_{6} \mathrm{H}_{5}$, 10H). Anal. Calcd for $\mathrm{C}_{13} \mathrm{H}_{12} \mathrm{Se}: \mathrm{C}, 63.16 \% ; \mathrm{H}, 4.89 \%$. Found: C, $62.57 \%$; H, $4.94 \%$.

\section{Synthesis of p-Methoxybenzyl p-Trimethylsilylphenyl} Selenide (2)

2 was prepared by the same method as for benzyl phenyl selenide (1) using $p$-trimethylsilylbromobenzene and $p$-methoxybenzyl chloride instead of bromobenzene and benzyl bromide, respectively. Yield was $26.6 \mathrm{~g}$ $(76.1 \%), \mathrm{mp} 86.5^{\circ} \mathrm{C} .{ }^{1} \mathrm{H} \mathrm{NMR}\left(\mathrm{CDCl}_{3}\right) \delta=0.22(\mathrm{~s}$, $\left.\left(\mathrm{CH}_{3}\right)_{3} \mathrm{Si}, 9 \mathrm{H}\right), 3.80\left(\mathrm{~s}, \mathrm{OCH}_{3}, 3 \mathrm{H}\right), 4.15\left(\mathrm{~s}, \mathrm{CH}_{2}, 2 \mathrm{H}\right)$, $6.60-7.60$ (br s, $2 \mathrm{C}_{6} \mathrm{H}_{4}, 8 \mathrm{H}$ ). Anal. Calcd for $\mathrm{C}_{17} \mathrm{H}_{22} \mathrm{O}-$ SeSi: C, $58.5 \%$; H, 6.3\%. Found: C, $58.43 \%$; H, $6.47 \%$.

\section{Photopolymerizations of Styrene and Methyl methacrylate with Selenides}

Required amounts of monomer and selenide were charged into a Pyrex tube. The tube was degassed under vacuum by conventional freeze and thaw, and sealed off under vacuum. All polymerizations were carried out by irradiation with Riko $100 \mathrm{~W}$ high pressure mercury lamp from $8 \mathrm{~cm}$ distance at room temperature. After a given time, the tube was opened and the contents were poured into a large amount of poor solvent. In the case of polymerization of styrene, the poor solvent was methanol. Hexane was used as a poor solvent in the case of polymerization of methyl methacrylate. The resulting polymers were purified by reprecipitation, followed by drying in vacuum.

\section{Synthesis of $\boldsymbol{P}-10$ by Oxidative Elimination of $\boldsymbol{P}-5$}

A solution of P-5 $(0.3 \mathrm{~g})$ and $30 \%$ aq hydrogen peroxide $(0.7 \mathrm{~g})$ in THF $(5.7 \mathrm{ml})$ was stirred for 1 week at room temperature. After evaporation of most of THF, the residue was poured into methanol to precipitate polymer. The polymer was purified by reprecipitation from methylene chloride with methanol, followed by drying in vacuum. Yield was $0.28 \mathrm{~g}(98 \%)$.

\section{Photopolymerization of Styrene with $\boldsymbol{P}-3$ as a Polymeric Photoiniferter}

A sample of P-3 $(0.6 \mathrm{~g})$, styrene $(9 \mathrm{ml})$, and benzene $(6 \mathrm{ml})$ was divided equally into three polymerization tubes. The solutions were irradiated with high pressure mercury lamp at room temperature. At approximate intervals, the reaction mixture was poured into methanol. The resulting polymer was dried in vacuum.

\section{Synthesis of Block Copolymers}

A solution of P-4 $(0.06 \mathrm{~g})$, methyl methacrylate $(3 \mathrm{ml})$ and benzene $(2 \mathrm{ml})$ in Pyrex tube was irradiated with high pressure mercury lamp at room temperature for $9 \mathrm{~h}$. The resulting polymer mixture was poured into methanol. Yield was $0.9 \mathrm{~g}$. Separation of the resulting whole polymers was carried out as follows. First, polystyrene was extracted from the resulting polymer $(0.67 \mathrm{~g})$ with of cyclohexane $(100 \mathrm{ml})$ by soxhlet extractor. Then, poly(methyl methacrylate) was extracted with a mixture of benzene and methanol $(10 \mathrm{ml}: 28 \mathrm{ml})$. The residue was dissolved with methylene chloride and poured into methanol. The resulting block copolymer was dried in vaccum. Yield was $0.38 \mathrm{~g}$. The polymer fractions thus extracted were examined by IR and ${ }^{1} \mathrm{H}$ NMR spectra.

\section{Measurements}

IR spectra were measured by a Nicolet Impact-400D. ${ }^{1} \mathrm{H}$ NMR spectra were recorded by a JEOL JNM-GX400 (400 MHZ) spectrometer with $\mathrm{CDCl}_{3}$ as solvent using tetramethylsilane as the internal standard. UV spectra were measured by a JASCO Ubest-35 spectrometer. Gel permeation chromatography (GPC) was performed on a TOSOH HLC-803D with G2000, G3000, and GMH TSK gel-columns and a differential refractometric detector using THF as an eluent. Molecular weights were determined using polystyrene standards. Differential scanning calorimetry (DSC) measurement was performed on a Rigaku Denki DSC-8230 at a heating rate of $10^{\circ} \mathrm{Cmin}^{-1}$. Elementary analysis was carried out with Yanaco CHN CORDER MT-3.

\section{RESULTS AND DISCUSSION}

Benzyl phenyl selenide (1) and p-methoxy benzyl $p$ trimethylsilylphenyl selenide (2) were prepared from the corresponding arylseleno magnesium bromide with benzyl bromide or $p$-methoxybenzyl bromide as shown in eq 3 .

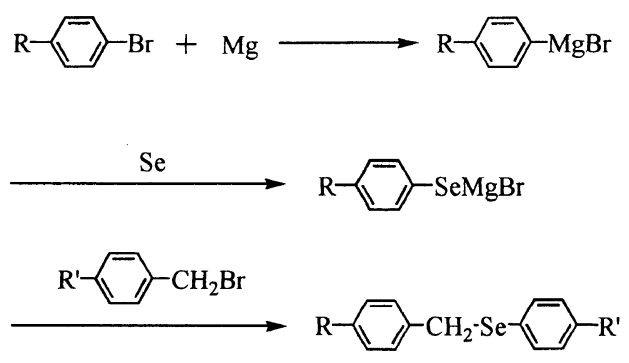

$$
\begin{array}{cl}
\text { 1, R= R'=H } & \stackrel{\mathrm{CH}_{3}}{1} \\
\text { 2, } \mathrm{R}=\mathrm{OCH}_{3}, \mathrm{R}^{\prime}= & \mathrm{Si}-\mathrm{CH}_{3} \\
& \stackrel{1}{\mathrm{C}} \mathrm{H}_{3}
\end{array}
$$

The UV spectra of these compounds had absorption bands in the range of $250-350 \mathrm{~nm}$ as shown in Figure 1. The polymerization of styrene was carried out by irradiation with a high pressure mercury lamp to the solution of styrene and $\mathbf{1}$ in a Pyrex tube at room temperature. The results are shown in Table I. The polymerizations proceeded smoothly in the presence of $\mathbf{1}$, but scarcely afforded polymers in the absence of 1 . The number average molecular weight $\left(\bar{M}_{n}\right)$ decreased with 
Table I. Photopolymerization ${ }^{\mathrm{a}}$ of styrene $(\mathrm{St})^{\mathrm{b}}$ and methyl methacrylate (MMA) ${ }^{\mathrm{c}}$ in the presence of benzyl phenyl selenide (1) or $p$-methoxybenzyl $p$-trimethylsilylphenyl selenide (2)

\begin{tabular}{|c|c|c|c|c|c|c|c|}
\hline Monomer & Selenide & $\begin{array}{l}{[\text { Selenide }]} \\
/[\text { Monomer }]\end{array}$ & $\frac{\text { Time }}{\mathrm{h}}$ & $\frac{\text { Yield }^{\mathrm{d}}}{\%}$ & $\begin{array}{c}\bar{M}_{n}^{\mathrm{e}} \\
\times 10^{-4}\end{array}$ & $\bar{M}_{w} / \bar{M}_{n}$ & Polymer \\
\hline St & None & 0 & 10 & 2.9 & 6.6 & 4.01 & P-1 \\
\hline St & 1 & 0.002 & 10 & 16.1 & 0.68 & 2.53 & P-2 \\
\hline St & 1 & 0.002 & 16 & 18.4 & 0.81 & 2.31 & P-3 \\
\hline St & 1 & 0.01 & 16 & 31.6 & 0.45 & 1.87 & P-4 \\
\hline St & 2 & 0.01 & 3 & 15.6 & 0.48 & 1.76 & P-5 \\
\hline MMA & None & 0 & 3 & 2.2 & 152.0 & 2.01 & P-6 \\
\hline MMA & 1 & 0.001 & 0.5 & 5.0 & 1.19 & 1.98 & P-7 \\
\hline MMA & 1 & 0.001 & 3 & 34.6 & 1.91 & 1.90 & P-8 \\
\hline
\end{tabular}

${ }^{\mathrm{a}} 100 \mathrm{~W}$ high pressure $\mathrm{Hg}$ lamp. ${ }^{\mathrm{b}}$ Styrene $=10 \mathrm{ml} .{ }^{\mathrm{c}} \mathrm{MMA}=10 \mathrm{ml}$. ${ }^{\mathrm{d}}$ Precipitated with methanol and hexane to polystyrene and PMMA, respectively. ${ }^{\mathrm{e}}$ Estimated by GPC.

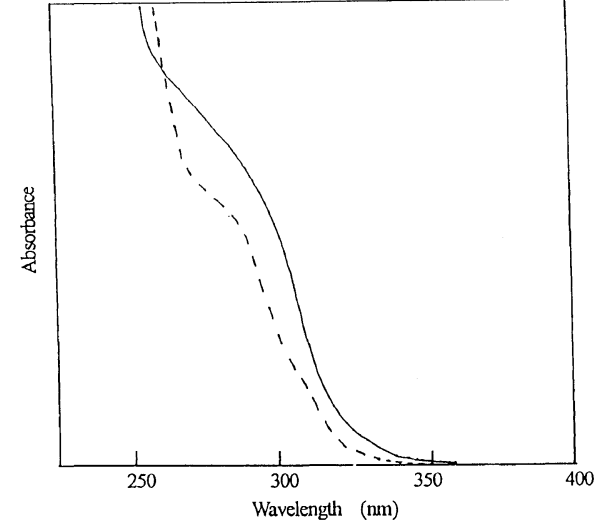

Figure 1. UV spectra of benzyl phenyl selenide (1, solid line) and $p$-methoxybenzyl $p$-trimethylsilylphenyl selenide (2, broken line).

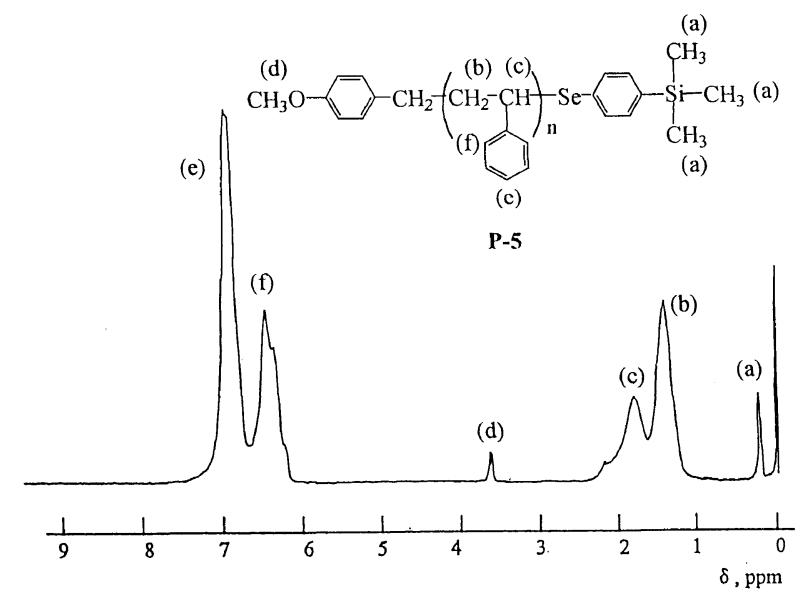

Figure 2. ${ }^{1} \mathrm{H}$ NMR spectrum $\left(400 \mathrm{MHz}\right.$, in $\left.\mathrm{CDCl}_{3}\right)$ of $\mathbf{P}-\mathbf{5}\left(\bar{M}_{n}=\right.$ 4780; $\bar{M}_{w} / \bar{M}_{n}=1.76$ ).

increasing 1. These results suggest that 1 not only works as a photoinitiator but also functions as a chain transfer agent. In fact, alkyl selenides are well known to undergo homolytic bimolecular substitution reaction $(\mathrm{SH} 2$ reaction) which corresponds to a chain transfer reaction in polymerization chemistry. ${ }^{31}$ The chain transfer constant of benzyl phenyl selenide for the polymerization of styrene with 2,2'-azobisisobutyronitrile (AIBN) at $60^{\circ} \mathrm{C}$ has been estimated as $1.04^{32}$ which is larger than value of diphenyl disulfide $(0.147) .{ }^{33}$

To investigate the end structure of polystyrene, 2 was used as a photoiniferter. ${ }^{1} \mathrm{H}$ NMR spectrum of the re- sulting polystyrene, P-5, is shown in Figure 2. Signals due to trimethylsilyl and methoxy groups are observed at 0.25 and $3.72 \mathrm{ppm}$, respectively. The ratio of peak intensities is 2.9. By comparing the number-average molecular weight from GPC with that from the peak intensity ratios of trimethylsilyl signal to the methine signal in the polystyrene backbone at $1.85 \mathrm{ppm}$, the average degree of functionality was calculated to be 0.95 . This indicates that polystyrenes prepared by this method contain benzyl group and arylseleno group at $\alpha$ - and $\omega$-chain ends, respectively.

To determine the terminal structure, the polymer, P-5 $\left(\bar{M}_{n}=4780, \bar{M}_{w} / \bar{M}_{n}=1.76\right)$, was treated with hydrogen peroxide in THF solution at room temperature on the basis of well-known fact that organo selenium compounds suffer syn elimination by oxidation and following degradation (eq 4). ${ }^{27}$ The resulting polymer P-10 $\left(\bar{M}_{n}=4540, \bar{M}_{w} / \bar{M}_{n}=1.75\right)$ was obtained in $98 \%$ yield.

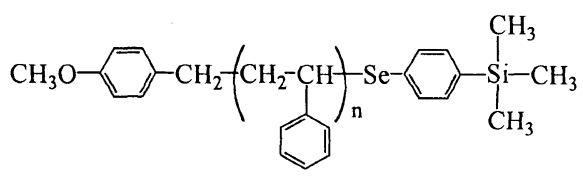

P-5

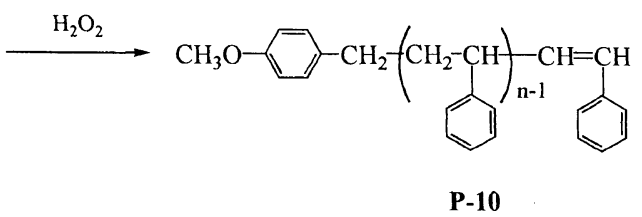

As seen in Figure $3,{ }^{1} \mathrm{H}$ NMR spectrum of $\mathbf{P}-10$ shows that the signal of the trimethylsilyl group at $0.25 \mathrm{ppm}$ completely disappeared. The signal of vinylene protons at $6.0-6.2 \mathrm{ppm}$ was observed and signals based on vinyl protons did not appear. The difference of $\bar{M}_{n}$ between P-5 and P-10 is very similar to the molecular weight of trimethylsilyl phenylselenol (228). Therefore, it is clear that the $\alpha$-chain end is a benzyl group and $\omega$-chain end is an arylseleno group. It can be considered that $\mathbf{1}$ also works as a photoiniferter similarly to 2 .

In the photopolymerization of styrene with $1(0.01 \mathrm{~mol}$ equiv. relative to monomer), conversion and $\bar{M}_{n}$ of the resulting polymers are plotted against polymerization time in Figure 4. Both values increased with reaction 


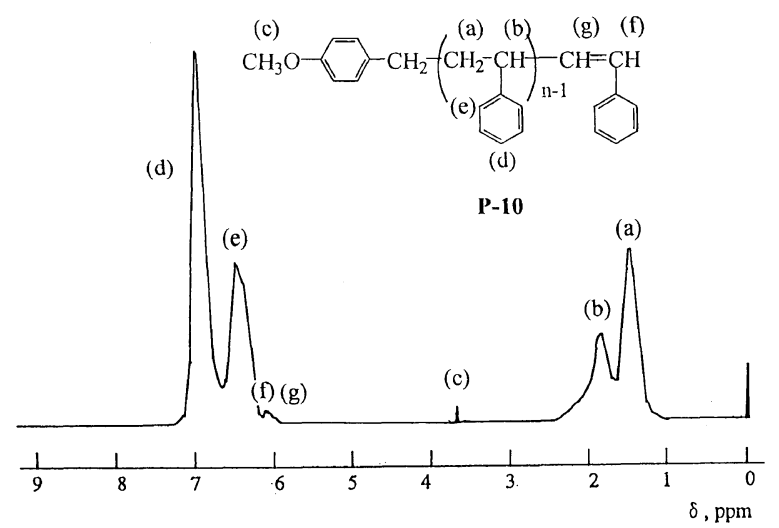

Figure 3. ${ }^{1} \mathrm{H}$ NMR spectrum $\left(400 \mathrm{MHz}\right.$, in $\left.\mathrm{CDCl}_{3}\right)$ of $\mathbf{P}-10\left(\bar{M}_{n}=\right.$ $\left.4540 ; \bar{M}_{w} / \bar{M}_{n}=1.75\right)$.

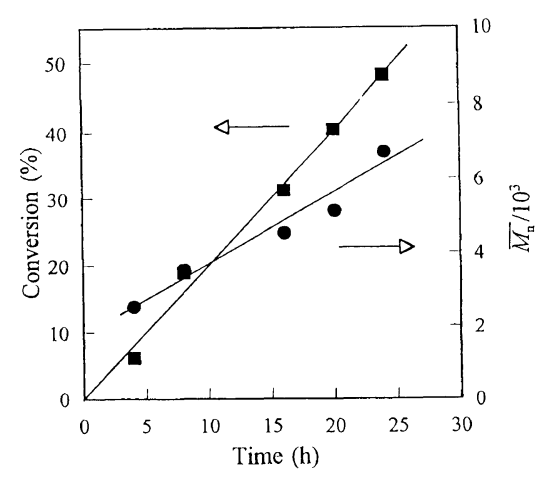

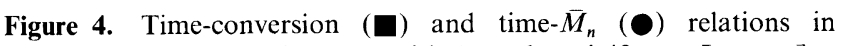
photopolymerization of styrene with $\mathbf{1}$ as phopoiniferter. [styrene]= $8.7 \mathrm{~mol} \mathrm{l}^{-1} ;[1]=0.087 \mathrm{~mol} \mathrm{l}^{-1}$.

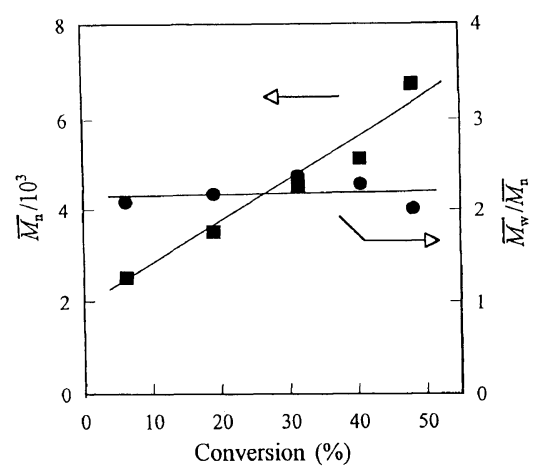

Figure 5. Conversion $-\bar{M}_{n}(\boldsymbol{\square})$ and conversion $-\bar{M}_{w} / \bar{M}_{n}(\bullet)$ relations for photopolymerization of styrene with $\mathbf{1}$ as phopoiniferter. $[$ styrene $]=8.7 \mathrm{moll}^{-1} ;[1]=0.087 \mathrm{~mol} \mathrm{l}^{-1}$.

time. The relationship between $\bar{M}_{n}$ and conversion showed that the $\bar{M}_{n}$ increased with conversion as shown in Figure 5. These results indicate that this polymerization shows a living-like nature in limited conversion ranges. It is well known that molecular weights of polymers obtained by conventional radical initiators are unchanged during polymerization.

Similar results were found for the photopolymerization of methyl methacrylate (MMA) with 1. (Table I). Here, 1 as photoiniferter of 0.001 molar equiv. relative to monomer was used. Polymer yields increased with polymerization time (Figure 6), and $\bar{M}_{n}$ increased with polymer yield (Figure 7). In Figures 5 and 7 , the $\bar{M}_{n}$ conversion lines did not intersect the origin of the graph.

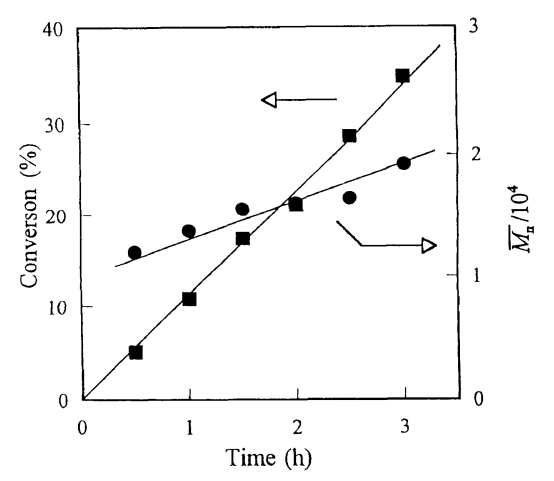

Figure 6. Time-conversion $(\square)$ and time- $\bar{M}_{n}(\bullet)$ relations in photopolymerization of MMA with 1 as phopoiniferter. [MMA] $=8.7$ mol $1^{-1} ;[1]=0.0087 \mathrm{~mol} \mathrm{l}^{-1}$.

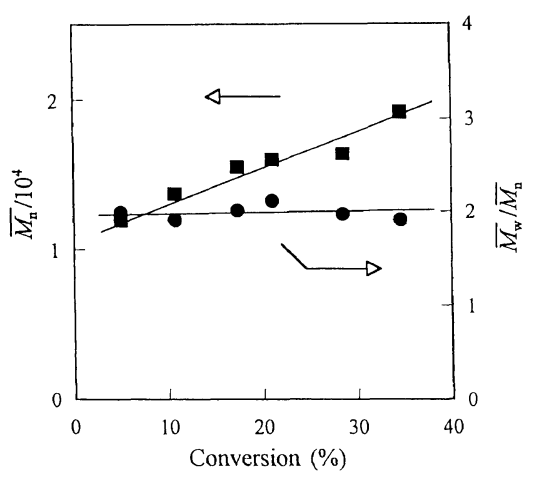

Figure 7. Conversion- $\bar{M}_{n}(\mathbf{\square})$ and conversion $-\bar{M}_{w} / \bar{M}_{n}(\boldsymbol{\bullet})$ relations for photopolymerization of MMA with $\mathbf{1}$ as phopoiniferter. [MMA] = $8.7 \mathrm{moll}^{-1} ;[1]=0.0087 \mathrm{moll}^{-1}$.

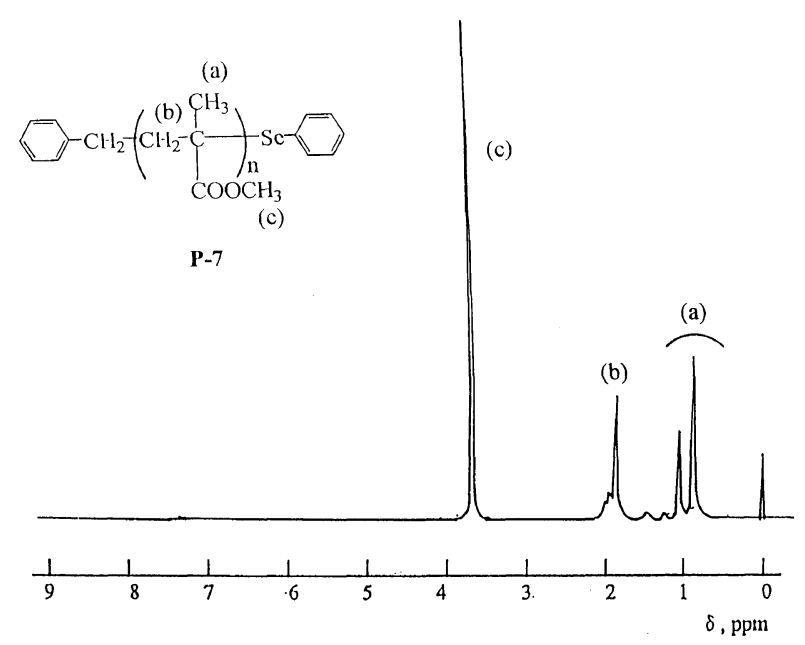

Figure 8. ${ }^{1} \mathrm{H}$ NMR spectrum $\left(400 \mathrm{MHz}\right.$, in $\left.\mathrm{CDCl}_{3}\right)$ of P-7 $\left(\bar{M}_{n}=\right.$ $\left.11900 ; \bar{M}_{w} / \bar{M}_{n}=1.98\right)$.

It seems that slight photopolymerization regardless of iniferter can not be negligible in the early step of the polymerization.

The ${ }^{1} \mathrm{H}$ NMR spectrum of the resulting poly(methyl methacrylate) (PMMA), P-7, is shown in Figure 8. From the signals of methyl group at $0.91,1.05$, and $1.22 \mathrm{ppm}$, the tacticity of PMMA was estimated as $r r / m r(r m) / m m$ : $61 / 31 / 8$. These values are very close to those of the one prepared using a typical radical initiators. ${ }^{34}$

The polymeric photoiniferter ability of the polystyrene prepared by this method was investigated. P-3 $(0.2 \mathrm{~g})$ with $3 \mathrm{ml}$ styrene was dissolved in $2 \mathrm{ml}$ benzene and 


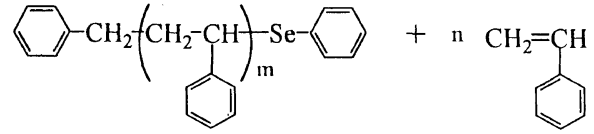

P-3

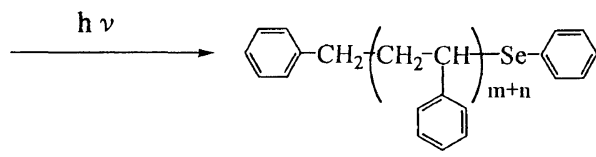

P-11

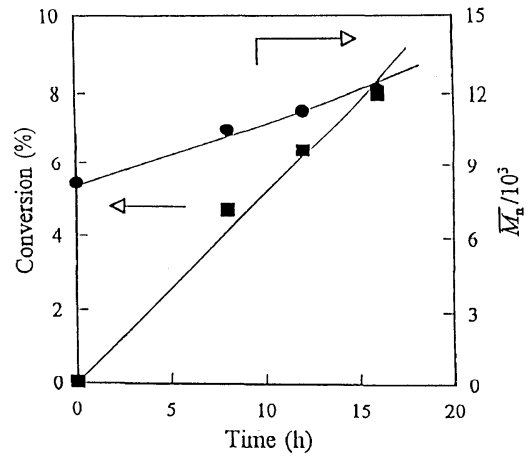

Figure 9. Time-conversion (ם) and time- $\bar{M}_{n}(\boldsymbol{\bullet})$ relations for photopolymerization of styrene with $\mathbf{P}-\mathbf{3}$ as a polymeric photoiniferter. [styrene $]=5.22 \mathrm{~mol} \mathrm{l}^{-1} ;[\mathbf{P}-3]=0.2 \mathrm{~g}$; benzene $=2 \mathrm{ml}$.

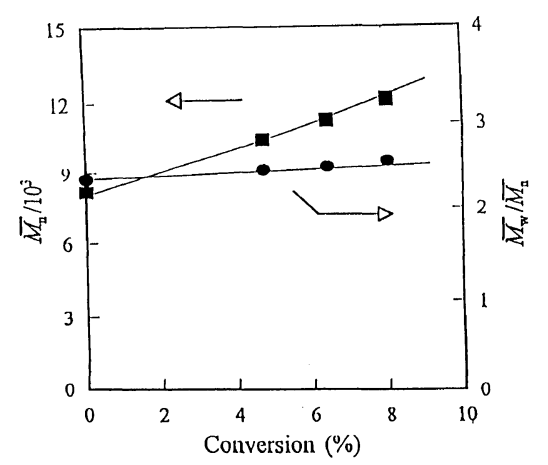

Figure 10. Conversion- $\bar{M}_{n}(\boldsymbol{\square})$ and conversion $-\bar{M}_{w} / \bar{M}_{n}(\mathbf{O})$ relations for photopolymerization of styrene with P-3 as a polymeric photoiniferter. [styrene $]=5.22 \mathrm{~mol} \mathrm{l}^{-1} ;[\mathbf{P}-3]=0.2 \mathrm{~g}$; benzene $=2 \mathrm{ml}$.

irradiated (eq 5). As can be seen from Figure 9, polymer yields and number-average molecular weights increased with irradiation time. $\bar{M}_{n}$ of resulting polymers increased with polymer yields (Figure 10). Here, polydispersities were almost unchanged $(2.31-2.54)$. These results show that polystyrene having a seleno group at $\omega$-chain end effectively works as a polymeric photoiniferter.

From the above results, in a limited range of conversion, photopolymerizations of styrene and methyl methacrylate with benzyl phenyl selenide showed to proceed as follows:

First, benzyl phenyl selenide would homolytically dissociate to benzyl radical and phenylseleno radical by photoirradiation (eq 6). ${ }^{28}$ The initiation of polymerization would occur by addition of benzyl radical, because the addition of the phenylseleno radical to monomer is very slow (eq 7). ${ }^{35-38}$ Propagation would take place by the addition of the resulting carbon radical to monomer.
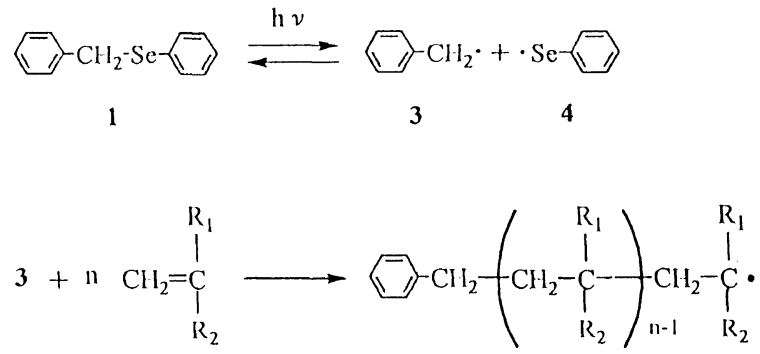

$\left[\begin{array}{c}\mathrm{R}_{1}=\mathrm{II}, \mathrm{R}_{2}=\mathrm{Pl} \\ \text { or } \\ \mathrm{R}_{1}=\mathrm{CH}_{3}, \mathrm{R}_{2}=\mathrm{COOCH}_{3}\end{array}\right]$

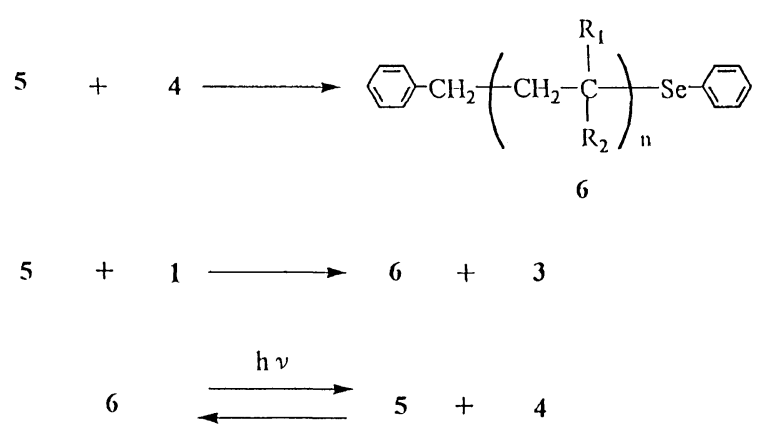

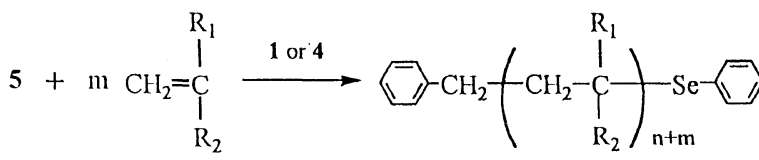

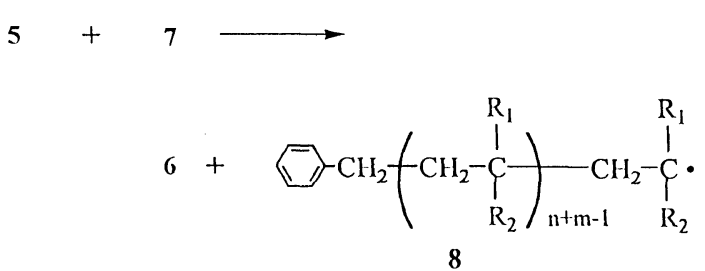

This polymerization would be terminated by two mechanisms. The one is the coupling of polymer radical with stable phenylseleno radical (eq 8), and the other is a chain transfer reaction to benzyl phenyl selenide or terminal phenyl seleno group in polymer, that is $\mathrm{SH} 2$ reaction (eq 9 and 12). ${ }^{39,40}$ Photoirradiation of the resulting polymer leads to the cleavage of benzylic carbon and selenium bond to afford less reactive phenylseleno radical and reactive polymeric carbon radical (eq 10). This polymeric radical attacks the carbon-carbon double bond in monomer (eq 11). Therefore, these are the essentially the same mechanisms proposed by Otsu et $a{ }^{41,42}$ for benzylthiuram sulfide as an photoiniferter except for the $\mathrm{SH} 2$ reaction.

From these facts, block polymerization of styrene with methyl methacrylate may proceed smoothly by this mechanism. So, to prepare the block copolymer, polystyrene(PSt)- $b$-PMMA, photopolymerization of MMA with P-4 as polymeric photoiniferter was carried out as shown in eq 13.

The produced polymer was separated by fractional precipitation using benzene and methanol to give a block copolymer. Yield of the isolated PSt- $b$-PMMA was $57 \mathrm{wt} \%$, and those of styrene homopolymer (homo-PSt) and MMA homopolymer (homo-PMMA) were $4 \mathrm{wt} \%$ 
T. S. Kwon et al.

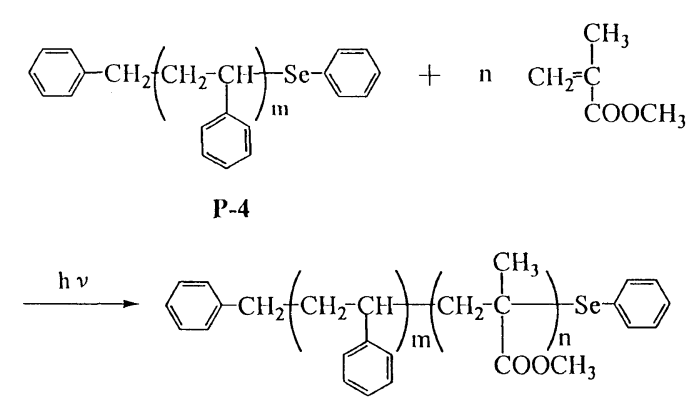

PSt- $b$-PMMA

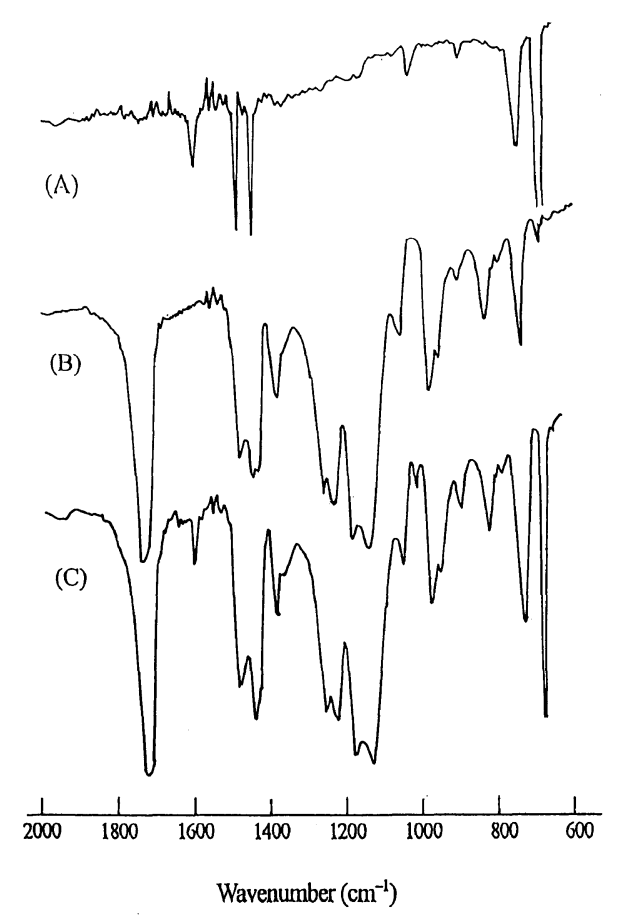

Figure 11. IR spectra of (a) homo-PSt (b) homo-PMMA (c) PSt- $b$ PMMA.

and $39 \mathrm{wt} \%$, respectively. Here, homo-PMMA is thought to be produced mainly by photoirradiation regardless of the initiator. The purified PSt- $b$-PMMA was characterized in detail by IR, GPC, ${ }^{1} \mathrm{H}$ NMR, and DSC measurements.

Figure 11 shows the IR spectra of homo-PSt (A), homo-PMMA (B), and PSt- $b$-PMMA (C). Figure 11(C) shows the strong band of carbonyl group at $1720 \mathrm{~cm}^{-1}$ attributed to PMMA segment and band of aromatic vibration at $1580 \mathrm{~cm}^{-1}$ attributed to PSt segment.

Figure 12 shows GPC curves for polystyrene prepolymer (C), the original products (B) of the block experiment and block copolymer (PSt-b-PMMA, (A)) separated by appropriate solvents as above mentioned. The curve of (A) shows an unimodal peak. Moreover, the $\bar{M}_{n}$ of block copolymer (A) is 8.7 times greater than that of the polystyrene prepolymer $(\mathrm{C})$.

The approximate composition of the block copolymer was determined from ${ }^{1} \mathrm{H}$ NMR (Figure 13). By comparing the relative ratio of methoxy protons at $3.72 \mathrm{ppm}$ of the MMA unit and phenyl protons at $6.3-7.2 \mathrm{ppm}$ of the styrene unit, the composition of the block copolymer was $10.5 \%$ PSt and $89.5 \%$ PMMA. These values agree with those obtained by GPC mea-

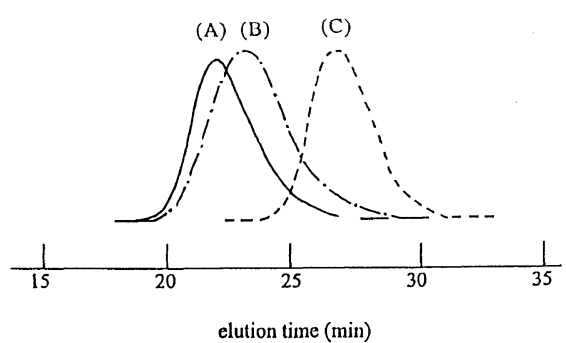

Figure 12. GPC profiles of PSt- $b$-PMMA ((A), $\bar{M}_{n}=42200 ; \bar{M}_{w} / \bar{M}_{n}=$ 2.13), original product without solvent fractionation ((B), $\bar{M}_{n}=19800$; $\left.\bar{M}_{w} / \bar{M}_{n}=3.03\right)$ and polystyrene as a prepolymer, P-4 ((C), $\bar{M}_{n}=4500$; $\left.\bar{M}_{w} / \bar{M}_{n}=1.87\right)$.

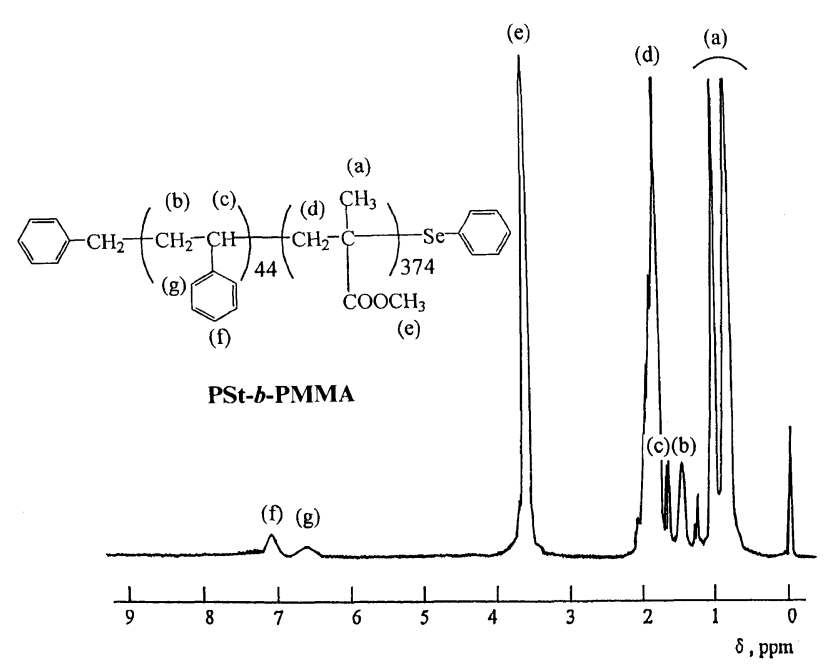

Figure 13. ${ }^{1} \mathrm{H}$ NMR spectrum $\left(400 \mathrm{MHz}\right.$, in $\left.\mathrm{CDCl}_{3}\right)$ of PSt- $b$ PMMA.

surement.

Finally, the glass transition temperature $\left(T_{\mathrm{g}}\right)$ of the resulting block copolymer was measured by DSC. $T_{\mathrm{g}} \mathrm{s}$ was found at $93^{\circ} \mathrm{C}$ due to polystyrene moiety and $120^{\circ} \mathrm{C}$ due to PMMA moiety. This can be explained by considering that the block copolymer forms micro phase separation structure.

It is thus clear that the A-B type block copolymer, PSt- $b$-PMMA, can be prepared using a polystyrene containing seleno group at $\omega$-chain end as polymeric photoiniferter.

\section{CONCLUSION}

Benzyl phenyl selenide (1) functions as a photoiniferter for the polymerization of styrene and methyl methacrylate. Investigation of end structure of polystyrene formed with $p$-methoxy benzyl $p$-trimethylsilylphenyl selenide (2) revealed that the resulting polymer contains benzyl group and arylseleno group at $\alpha$ - and $\omega$-chain ends, respectively. Photoirradiation of polystyrene having phenylseleno group at $\omega$-chain end as polymeric photoiniferter in methyl methacrylate afforded a block copolymer of styrene and methyl methacrylate.

\section{REFERENCES}

1. K. Takenaka, A. Hirao, and S. Nakahama, Macromol. Chem. Phys., 196, 1687 (1995).

2. R. P. Quirk and L. F. Zhu, Makromol. Chem., 190, 487 (1989). 
3. H. Shohi, M. Sawamoto, and T. Higashimura, Macromolecules, 25, 53 (1992).

4. H. Shohi, M. Sawamoto, and T. Higashimura, Macromolecules, 25, 58 (1992).

5. M. K. Mishara and J. P. Kennedy, Polym. Bull., 17, 7 (1987).

6. K. Ito, N. Usami, and Y. Yamashita, Macromolecules, 13, 216 (1980).

7. Y. Chujo, A. Hiraiwa, and Y. Yamashita, Makromol. Chem., 185, 2077 (1984).

8. E. Yoshida and A. Sugita, Macromolecules, 29, 6422 (1996).

9. K. S. Murthy and K. Kishore, J. Polym. Sci., Polym. Chem. Ed., 34, 1415 (1996).

10. G. F. Meijs, T. C. Morton, E. Rizzardo, and S. H. Thang, Macromolecules, 24, 3689 (1991).

11. W. Heitz, Makromol. Chem., Macromol. Symp., 10/11, 297 (1987).

12. J. Harmon, T. A. Ford, W. E. Hanford, and R. M. Joyce, J. Am. Chem. Soc., 72, 2213 (1950)

13. J. W. Breitenbach, O. F. Olaj, K. Kuchner, and H. Horacek, Makromol. Chem., 87, 295 (1965).

14. D. Colombani, M. O. Zink, and P. Chaumont, Macromolecules, 29, 819 (1996)

15. B. Yamada, S. Kobatake, and S. Aoki, Macromolecules, 26, 5099 (1993).

16. T. Otsu, T. Matsunaga, T. Doi, and A. Matsumoto, Eur. Polym. J., 31, 67 (1995).

17. T. Otsu and M. Yoshida, Makromol. Chem., Rapid Commun., 3, 127 (1982)

18. T. Otsu, M. Yoshida, and T. Tazaki, Makromol. Chem., Rapid Commun., 3, 133 (1982).

19. K. Endo, K. Murata, and T. Otsu, Macromolecules, 25, 5554 (1992).

20. T. Otsu, J. Polym. Sci., 26, 236 (1957).

21. T. Otsu, J. Yonezawa, and M. Imoto, Makromol. Chem., 36, 93 (1960).

22. T. Otsu and M. Yoshida, Polym. Bull., 7, 197 (1982).

23. T. Otsu, A. Kuriyama, and M. Yoshida, Kobunshi Ronbunshu.,
40, 583 (1983)

24. T. S. Kwon, S. Kumazawa, T. Yokoi, S. Kondo, H. Kunisada, and Y. Yuki, J. Macromol. Sci. Pure Appl. Chem., A34, 1553 (1997)

25. T. Otsu, M. Yoshida, and A. Kuriyama, Polym. Bull., 7, 45 (1982).

26. C. G. Gutierrez, R. A. Stringham, T. Nitasaka, and K. G Glasscock, J. Org. Chem., 45, 3393 (1980).

27. K. B. Sharpless, M. W. Young, and R. F. Lauer, Tetrahedron Lett., 22, 1979 (1973).

28. Y. C. Chu, D. G. Marsh, and W. H. H. Gunther, J. Am. Chem. Soc., 97, 4905 (1975).

29. E. B. Stephens, K. E. Kinsey, J. F. Davis, and J. M. Tour, Macromolecules, 26, 3519 (1993).

30. P. G. Gassman, T. Miura, and A. Mossman, J. Org. Chem., 47, 954 (1982)

31. G. A. Russell and H. Tashtoush, J. Am. Chem. Soc., 105, 1398 (1983).

32. T. S. Kwon, S. Kondo, H. Kunisada, and Y. Yuki, unpublished results.

33. T. Otsu and H. Motooka, Kogyo Kagaku Zasshi, 62, 137 (1959).

34. F. A. Bovey and G. V. D. Tiers, J. Polym. Sci., 44, 173 (1960).

35. T. Sato, M. Abe, and T. Otsu, Makromol. Chem., 178, 1951 (1977).

36. T. Sato, M. Abe, and T. Otsu, Makromol. Chem., 180, 1165 (1979).

37. O. Ito and M. Matsuda, J. Am. Chem. Soc., 101, 5732 (1979).

38. O. Ito and M. Matsuda, J. Am. Chem. Soc., 103, 5871 (1981).

39. J. C. Scaiano and K. U. Ingold, J. Am. Chem. Soc., 99, 2079 (1977).

40. Y. Okamoto, K. L. Chellappa, and R. Homsany, J. Org. Chem., 38, 3172 (1973).

41. T. Otsu and A. Kuriyama, Polym. Bull., 11, 135 (1984).

42. T. Otsu and A. Kuriyama, J. Macromol. Sci. Chem. Ed., A21 961 (1984). 